\title{
The Economic Roots of Anti-Immigrant Prejudice in the Global South: Evidence from South Africa
}

\author{
Adam S. Harris ${ }^{1}$ \\ University College London \\ 30 Tavistock Square, \\ Bloomsbury, London \\ WC1H 9QU, UK \\ asharris4@gmail.com \\ adam.s.harris@ucl.ac.uk \\ +442076794999 \\ Michael G. Findley \\ University of Texas at Austin \\ 3.108 Batts \\ Austin, TX, 78712 \\ mgfindley@gmail.com \\ +15122327208 \\ Daniel L. Nielson \\ Brigham Young University \\ 790 SWKT \\ Provo, UT, 84606 \\ dan_nielson@byu.edu \\ +18014223417 \\ Kennard L. Noyes \\ University of Virginia \\ 580 Massie Rd, \\ Charlottesville, VA 22903 \\ kennardnoyes@gmail.com
}

\footnotetext{
${ }^{1}$ Replication data for this article are available on the author's website, here: https://adamsharrisblog.wordpress.com/research/
} 


\begin{abstract}
Most research in developed countries on prejudice toward foreign-born minorities suggests that cultural rather than economic threat motivates xenophobia. Prior studies leave unanswered questions about the origins of anti-immigrant prejudice in developing countries, where one-third of worldwide immigration occurs. Alternatively, developing-country research simply assumes that economic threat drives prejudice in the Global South but has not presented credible empirical evidence. In this study, we seek to reliably measure anti-immigrant prejudice and examine possible determinants of prejudice and prejudice-based voting behavior. Through a list experiment conducted on a random sample of South Africans $(\mathrm{N}=1,088)$, we investigate the predictive power of economic threat theory in explaining prejudice toward immigrants in South Africa. The results show that significant prejudice towards immigrants exists among South Africans and that such prejudice is higher among the unemployed, but these sentiments do not seem to influence vote choice. The evidence suggests that the determinants of anti-immigrant sentiments due to South-South migration are distinct from South-North migration.
\end{abstract}

Key words: South Africa, immigration, xenophobia, economic threat, voting 
In early 2015, violence against immigrants erupted in South Africa, resulting in the deaths of seven immigrants, the displacement of thousands, and military intervention to stop the attacks (Al Jazeera 2015b, Nicolson 2015). Yet President Jacob Zuma reassured the world that South Africans are "generally not xenophobic," and thousands of citizens took to the streets to protest the violent outbreaks and the prejudice motivating them (Al Jazeera 2015a, 2015b). However, prior patterns in the country suggest that xenophobia may be widespread, though the evidence is anecdotal rather than systematic. Indeed, the 2015 violence was only one of the most recent anti-immigrant attacks in the country. In May 2008 at least 70 immigrants were killed at the hands of rioting South Africans, and thousands of immigrants were displaced (Misago et al 2009), and a number of attacks and anti-immigrant protests took place in February 2017.

Scholarly attention to anti-immigrant sentiments has arisen in the context of a diversifying Europe and the rise of extremist right parties (Sniderman 2004, Sides and Citrin 2007). However, according to the United Nation's International Migration Report of 2013, South-South migration is as common as South-North migration. Roughly 36\% of the global world migration takes place within the global South and 35\% from the global South to the North (United Nations 2013). Although anti-immigrant sentiments are common throughout the world, scholarly attention to the dynamics in developing countries lags behind, begging the question of what drives South-South xenophobic sentiments and behavior. In addition, anti-immigrant, far right parties have not emerged in developing countries like they have in Europe, and yet there exists strong and widespread anti-immigrant sentiment in much of the developing world (Crush and Ramachandran 2010, Adida 2014). It seems that politicians have not exploited these feelings in order to gain political support. Do anti-immigrant sentiments translate into political 
preferences in the developing world, as they seem to do in many developed democracies? This paper takes a first step in answering this question.

Existing explanations for anti-immigrant attitudes and behaviors are rooted in theories of economic and cultural threat with the preponderance of evidence pointing towards cultural considerations and only to a lesser extent to personal economic motivations (Hainmueller and Hopkins 2014). Some research nonetheless identifies the importance of economic considerations with an emphasis on competition for jobs (Scheve and Slaughter 2001, Hainmueller and Hiscox 2007, Misago et al 2009). In sum, however, studies in developed countries mostly provide systematic evidence in support of the cultural origins of xenophobia, whereas research on developing countries, including South Africa, have not systematically or reliably investigated the economic or cultural sources of anti-immigrant prejudice. Given that most evidence suggests that economic threat drives anti-immigrant sentiment in the developing world (i.e., Misago et al 2009), we focus our study on investigating the explanatory power of economic threat while controlling for culture threat in order to test the conventional wisdom that economic competition for jobs drives anti-immigrant prejudice in the global South.

We employed two list experiments to address social-desirability bias in admitting prejudiced attitudes in South Africa. We first measure the level of anti-immigrant sentiment using the list-experimental technique and show that widespread prejudice does indeed appear to exist in the country beyond the relatively few perpetrators of the recent violence. Through subgroup analysis we then consider the main determinants of prejudice toward immigrants and show that sensitivity to the item measuring xenophobia in the list experiment varied systematically across categories of employment status. Indeed, we find that the unemployed are significantly more likely to feel prejudice toward immigrants. This finding provides systematic, 
empirical support to claims that economic threat is correlated with prejudice against immigrants in South Africa (i.e. Scheve and Slaughter 2001). To our knowledge this is the first systematic study of the role played by economic conditions in anti-immigrant prejudice in the Global South.

Although we find that unemployment appears to be a key correlate of prejudice toward immigrants, this prejudice does not appear to translate into political behavior as manifested in willingness to vote for parties who propose stricter immigration laws. We find that although the unemployed are more likely to be angered over immigrants moving into their communities, they are not more likely to support candidates who favor anti-immigrant laws.

The paper is organized as follows. The next section reviews the literature and theories of prejudice highlighting in particular economic threat theory. The following section provides contextual details about South Africa, including its history of anti-immigrant violence. The experimental research design and data are then presented followed by the analysis and results, which show that anti-immigrant prejudice (1) clearly exists in South Africa, (2) is best explained by economic threat, but (3) does not appear to correlate with prospective voting behavior. The final section concludes with a discussion of external validity and the limitations of the study.

\section{Theorizing Prejudice}

\section{Economic Threat Theory}

Economic threat theory contends that prejudice results from competition over scare resources of which jobs are the most salient (Koopmans 1996, Luttmer 2001, Fetzer 2000, Oliver and Mendelberg 2000, Scheve and Slaughter 2001, Esses et al 2001, Scheepers et al 2002, Hanson et al 2007, Bekker et al 2008, Dancyeiger 2010, Landau 2010). Others have found that relative skill levels of natives and migrants matter (Mayda 2006) and that increased education 
levels may moderate prejudice, as education is positively correlated with favorable attitudes toward immigration (Hainmueller and Hiscox 2007, Chandler et al 2001).

Studies of immigrant prejudice in South Africa present anecdotal and qualitative evidence showing that South Africans are generally prejudiced toward immigrants. These studies suggest that socio-economic circumstances such as relative deprivation are important determinants of immigrant prejudice. This is inferred from the fact that the attacks noted above took place largely in poor areas (Croucher 1998, Hassim et al 2008, Misago et al 2009). Methodologically, the studies arguing that xenophobia is economically driven use expert, victim, perpetrator, and civilian interviews (i.e. Misago et al 2009) or historical, theoretical, or normative analyses (Croucher 1998, Crush 2000). Given these studies, South Africa's economic challenges, history of xenophobic violence, and high unemployment rate all suggest circumstantial evidence that immigrants are perceived as an economic threat by low-skilled, unemployed, less-educated, and poor South Africans. However, this evidence is merely suggestive and would benefit from an approach that can both overcome the measurement bias associated with social desirability and that is more able to adjudicate systematically between competing accounts of xenophobia. This study seeks to fill this gap using a survey experiment. Given the anecdotal evidence of economic threat in South Africa, we hypothesize the following:

Economic Threat Hypothesis: Individuals who feel economically threatened (those with lower socio-economic status, namely the unemployed) will have higher levels of immigrant prejudice than those who are not economically threatened.

While this is our core hypothesis, we also consider a number of alternative drivers of antiimmigrant prejudice and control for them in the analysis below to more fully isolate the effect of economic threat.

Alternative Drivers of Anti-Immigrant Prejudice 
In this section, we present three alternative drivers of anti-immigrant prejudice: culture threat, contact with immigrants, and low education. First, a number of studies show that immigrants and other minorities threaten national identity and culture and thus become important objects of negative and discriminatory attitudes (Sniderman et al 2004, Sides and Citrin 2007, McLaren and Johnson 2007, Green and Seher 2003, Brown 2010, Ford 2011, Hainmueller and Hangartner 2013). In addition, studies in social identity theory show that as people more strongly identify with their own ethnic (or other social) group, they develop more negative attitudes toward other groups (Tajfel 1981, Capozza and Brown 2000, Huddy 2001).

Second, contact theory argues that prejudice is a result of ignorance about other groups and therefore more positive, frequent, and meaningful contact among groups should reduce prejudice (Allport 1954). However, support for contact theory is mixed (Citrin et al 1997, Fetzer 2000, Bahry 2005, Schmid et al 2008, Kopstein and Wittenberg 2009, Rocha and Espino 2009). One challenge of contact theory is that contact is endogenous to prejudice - that is, prejudiced people generally choose to avoid members of the out-group. ${ }^{2}$

And finally, education is often a marker of socio-economic status and thus is used as a proxy for economic threat in many studies, but levels of schooling capture more than economic status alone. In this study, we do not treat education as a proxy for economic threat, because education has been found to reduce prejudice through developing more sophisticated cognitive processes and opening minds (Sniderman et al 1984, Bobo and Licari 1989, Hello et al 2002, Hello et al 2006). It thus seems that education would reduce immigrant prejudice. In South

\footnotetext{
${ }^{2}$ Hopkins (2010) provides a novel way in which to study contact theory and anti-immigrant sentiments in the US using exogenous shocks such at the $9 / 11$ attacks in the US.
} 
Africa, however, immigrants face an intense, pervasive, and emotional prejudice against them (Crush 2000, Hassim et al 2008), which may be hard to reduce through education alone.

\section{Prejudice and Political Preferences}

As noted above, anti-immigrant prejudice seems to play an important role in politics in Europe and the United States. Europe has seen the rise of numerous far right, anti-immigrant parties that have often gained non-negligible support at the polls (Dancyeiger 2010), and the US saw the success of Donald Trump in the 2016 elections due, at least in part, to his promise to build a wall between the US and Mexico and prohibit the immigration of Muslims into the country. However, there are no examples to our knowledge in which an anti-immigrant party has gained notable support in an election in a developing democracy. In fact, while anti-immigrant sentiment has risen in developing countries such as South Africa and India (Crush and Ramachandran 2010), we have not seen the same rise in anti-immigrant parties. Therefore, how does anti-immigrant sentiment influence political preferences when there is no clear antiimmigrant party? This is an especially important question given that far right, anti-immigrant parties play an important role in putting immigration at the forefront of politics (Meguid 2005, Wagner and Meyer 2017).

Numerous studies investigate the role of prejudice on attitudes toward immigration policy (Fetzer 2000, Sinderman et al 2004, Blinder et al 2013) and on support for far right parties in Europe (Van der Brug et al 2000, Werts et al 2012, Hainmueller and Hangartner 2013). ${ }^{3}$ However, surprisingly few studies directly study the role of prejudice on vote choice or voter mobilization beyond the investigation of support for the far right. This is likely the result of the

\footnotetext{
${ }^{3}$ While there is a general trend for anti-immigrant sentiment to lead to support for anti-immigrant parties, this is not the case in all European countries (see van der Brug et al (2005) and Mudde (2011).
} 
literature's focus on Europe, but this focus has caused us to overlook the way that anti-immigrant sentiment influences vote choice for mainstream parties elsewhere (with the exception of Meguid 2005). In our case of interest, South Africa, it is unclear whether or not anti-immigrant sentiment will influence vote choice because 1) the one anti-immigrant party that currently exists has sufficiently politicized these sentiments, which suggests attitudes toward immigrants will not influence vote choice, but 2) South Africa is a dominant party system that has one of the largest economies on the continent and is highly ethnically diverse, which suggests that anti-immigrant sentiments may likely be politicized for some individuals (Whitaker and Giersch 2015) and thus could potentially influence vote choice. Anti-immigrant attitudes may not always translate into political preferences, and we test to see whether this is, in fact, the case in South Africa.

It is important to note that, due to the electoral dominance of the ANC and the relatively minor role that policy is perceived to play in South Africa's elections, a party's stance on immigration may not significantly influence election outcomes. However, immigration itself is an important issue that could influence citizen vote choices. First, economic conditions are poor for many people and the ruling party experienced its poorest performance to date in the 2016 local elections. In such a context, scapegoating of immigrants is likely very appealing, which may have helped to spark the violence and anti-immigrant protests in February 2017. Second, the formation of the anti-immigrant South Africa First party in April 2013 by expelled ANC members shows that there is some expectation from politicians that anti-immigrant stances are potentially a fruitful way to gain support. Third, Afrobarometer data suggests that South Africans are unsatisfied with how the government is currently managing immigration at least in part due to the economic considerations. From the Round 6 data (2016), 67\% of respondents say that the government poorly manages immigration and 52\% agree that "South Africa's immigration 
policies should favour exceptionally skilled foreigners and foreign investors to help the economy grow".

\section{South Africa as Study Location}

South Africa, as one of Africa's biggest economies and with one of the most affluent (yet unequal) populations on the continent, is an attractive destination for many African migrants. The number of international immigrants to South Africa has steadily risen since 2000 and was estimated to be 2.2 million in 2015 (Wilkinson 2015). According to Crush and Ramachandran (2010), most immigrants to South Africa are low-skilled and poor. The vast majority of immigrants come from South Africa's neighbors: Mozambique, Zimbabwe, and Lesotho. They primarily move into the townships (former Apartheid-era black-only areas) or inter-city areas of South Africa.

We conducted the survey in, and focus our analysis on, South Africa's townships for a number of reasons. First, immigration from other African countries is an important political, human rights, and security concern in South Africa's townships (Hassim et al 2008). Second, most of the anti-immigrant violence in the last 10 years has taken place in urban townships. Third, South Africa's townships are also the most likely to be economically threatened and, therefore, if economic threat operates as a determinant of anti-immigrant sentiment in South Africa, we should observe it in the townships.

\section{Data and Experimental Design}

To explore the questions detailed above, we conducted a survey and list experiment to test the effect of economic threat on ethnic and immigrant prejudice. In July 2009, we recruited a 
random sample 4 of black South Africans from three townships in South Africa: Daveyton in Johannesburg, Gauteng Province; Mdantsane in East London, Eastern Cape Province; and Umlazi in Durban, Kwa-Zulu Natal Province. ${ }^{5}$ To increase the sample size and provide the statistical power to perform multivariate regression estimates using the ICT method (Blair and Imai 2012), we conducted a second round of the survey in Daveyton in July 2011. In total, we completed the study with 1,088 subjects. ${ }^{6}$

We chose the three research sites to maximize representativeness in terms of xenophobic violence and ethnic diversity. First, these three townships have experienced and are located in municipalities and provinces that have experienced different levels of xenophobic attacks since 1994 (Misago et al 2009): high levels in Daveyton, moderate levels in Umlazi, and low levels in Mdantsane (see Appendix A for additional information). Choosing these three townships is thus an attempt to ensure that the sample contains variation on the dependent variable of immigrant prejudice. ${ }^{7}$ Notably, Umlazi, which is in the city of Durban, is one of two locations most hit by xenophobic violence in early 2015 . It is important to note that due to safety concerns, we

\footnotetext{
${ }^{4}$ The sampling procedure was a typical random walk procedure.

${ }^{5}$ The survey was conducted in primarily black areas because these areas have seen the most xenophobic violence. Given funding limitations, we were not able to conduct a survey of the broader South African population. Our conclusions, therefore, are confined to the black population. While there are key differences and similarities across these locations, they are not necessarily well positioned for either a most similar or most different case comparison. For our purposes, we selected as many locations as feasible in order to gain representation across as many municipalities and provinces as possible. While not perfect, we feel that this geographic spread and the differences and similarities across the municipalities provides enough diversity for the results to speak to the determinants of xenophobic attitudes for the modal Black South African.

${ }^{6}$ See Table A3 in Appendix A for the proportion of the sample from each year/location.

${ }^{7} \mathrm{We}$ expect that immigrant prejudice and xenophobic attacks are positively correlated.
} 
selected away from areas most hard-hit by xenophobic violence, which brings in some selection bias but likely only downwardly biases the results as effects are likely larger in areas with more violence.

Second, we wanted to take into account various different ethnic contexts in South Africa because ethnicity matters for both political preferences and contact, which in turn is important for prejudice. While South Africa's townships, on average, are fairly similar in terms of socioeconomic indicators (of which these townships are representative; see Appendix A), townships in South Africa vary in ethnic makeup. We chose Daveyton because its ethnic composition very closely approximates the national ethnic makeup of the black South African population (Statistics South Africa 2001). While many townships in Johannesburg, such as Daveyton, are quite diverse, many townships are fairly homogenous, including the other two townships in our study: Mdantsane and Umlazi. We chose these two townships because they are homogenous with respect to the two largest ethnic groups: Xhosas make up about $90 \%$ of the Mdantsane population and Zulus make up 75\% in Umlazi (Statistics South Africa 2001).

\section{List Experiment Design}

To reliably measure anti-immigrant prejudice, we employed a list experiment, a tool developed to investigate sensitive issues in surveys in which social desirability likely biases

responses (Kuklinski et al 1997, Glynn 2013). In list experiments, subjects are randomly assigned to receive two nearly identical lists of items and asked to count - but not report individually - the items of the list that, for example, make them angry or influence their vote. The control list only contains innocuous response options while the treatment list contains the exact same innocuous options but adds one sensitive option. This is done so that respondents can 
feel more comfortable honestly reporting prejudice because they only report the number of options that make them angry or influence their vote. Therefore, the enumerator does not know which specific items were selected by any given subject. ${ }^{8}$ Because the treatment and control lists are randomly assigned, in expectation all other covariates are balanced across conditions and only the added sensitive item varies from one condition to the other.

In our study, each respondent participated in two list experiments. List Experiment 1 asked "How many of the following make you angry?". Subjects were randomly assigned to receive one of two lists. The sensitive item was "Immigrants moving into your community". List Experiment 2 asked "How many of the following influenced your vote in the recent national elections?". The sensitive item was "Candidate or party promises to stop immigration". The exact wording of the list experiments appears in Figure 1 below. ${ }^{9}$

[Figure 1 Here]

The Anger Experiment only measures a certain aspect of immigrant prejudice: anger over foreigners moving into the community. At first glance it appears that anger over immigrants moving into one's neighborhood only addresses proximity and relative size of groups of foreigners in a community, but we note that it also represents more diverse aspects of xenophobia that are especially important in the South African context. Immigrants moving into the community can represent more competition for social services such as housing, an infiltration of outsiders into people's intimate social space, or the introduction of outside cultural influences.

\footnotetext{
${ }^{8}$ While list experiments do reduce response bias, we are aware they come with their own challenges such as high cognitive burden and satisficing (Kramon and Weghorst 2012). The results should of course be interpreted with these limitations in mind.

${ }^{9}$ The wording was chosen to maximize understanding among a population that speaks English as a second language and facilitate easy translation by enumerators.
} 
Given that we control for culture threat, if economic variables can predict a positive response to this sensitive item while the culture threat variables do not, then we interpret this as support for economic threat theory.

These two experiments were designed specifically to test prejudice and its effects on political preferences. The Anger Experiment is meant to capture negative feelings toward immigrants in a very proximate and personal way: the perceived "invasion" of foreigners into a community. The Voting Experiment was meant to test whether or not these negative feelings toward immigrants influence political preferences. Therefore, the Anger Experiment provides a measure of prejudice toward immigrants in the form of selecting the sensitive item in the treatment condition. This constitutes our dependent variable of immigrant prejudice. The Voting Experiment provides a measure of the effect of anti-immigrant prejudice on political preference formation: those who consider anti-immigrant stances of politicians (whether they vote for or against anti-immigrant politicians) allow the prejudices to influence their vote choice. Therefore, we have a measure of the influence of immigrant prejudices on prospective vote choice.

\section{Independent Variables}

To operationalize indicators of economic threat theory, we measure the skill and economic status of the subjects. We expect that individuals with lower skill sets and poorer

economic circumstances are more likely to feel threatened and thus hold prejudice toward immigrants. We use two dummy variables to measure economic circumstance and skill: low income and unemployed. In addition, water source proxies for socio-economic status and is measured as a dummy variable for a private water source. People who must access their water from a public source (public tap, river, etc) are generally worse off economically than those who 
have plumbing. ${ }^{10}$ We chose these three measures and investigate the effect of each because we feel they capture different aspects of economic wellbeing and threat. For example, if we estimate the effect of unemployment while controlling for income and water source, we are able to detect the effect of unemployment itself while controlling for variation in terms of individuals' abilities to find some form of income (state assistance, informal/temporary jobs) and their general economic conditions (one can be unemployed and still live in a home that has a private water source). If unemployment is a significant predictor of anti-immigrant sentiment rather than water source, we can conclude that the desperation of unemployment rather than lower economic circumstances drives the feeling of threat.

We use education to capture the cognitive development aspects of education (the isolation of the cognitive component of education is possible because we include the employment and income variables as controls in the regression analysis). Education is measured using three dummy variables that indicate the person's highest level of education: did not complete high school, completed high school, and any tertiary education. ${ }^{11}$

To control for contact, we administered the Multi-Ethnic Identity Measure (MEIM; see Phinney 1992) to measure each subject's amount of contact with out-groups. This instrument asks twenty questions regarding how the subject feels toward her ethnic group and out-groups. The subjects' responses to five key MEIM questions are averaged to yield a contact score in the

\footnotetext{
${ }^{10}$ Other measures of socio-economic status were considered such as the type of house a person lives in, but water source was chosen for analysis because it is the most straightforward measure. In addition, results are robust to the type of house measure.

${ }^{11}$ The results (both the difference of means and ICT estimation) are robust to various other codings of the education variable (different dummy divisions and an index indicator that is a continuous variable). This was the most parsimonious coding and thus was chosen for use in analysis.
} 
set $[1,4]$ (see Appendix B calculation procedures). The higher an individual's contact score, the more positive contact the individual has had with non-co-ethnics. The survey questions simply ask about contact with non-co-ethnics generally, but not immigrants specifically. If respondents answer this question with only non-co-ethnic South Africans in mind, in order for this to be a measure of contact with immigrants, we have to assume that those with more (less) contact with non-co-ethnic South Africans also have more (less) contact with immigrants. It seems reasonable to assume that contact with non-co-ethnic South Africans and immigrants is highly positively correlated.

We also include a variable for survey location, Daveyton, as this would be important for contact with different people as it is the most heterogeneous of the studied townships. The Daveyton variable, which is an indicator that takes the value of 1 if the individual lives in Daveyton at the time of the study (and 0 otherwise), controls for whether or not the subject lives in a homogenous (Daveyton $=0$ ) or heterogeneous (Daveyton $=1$ ) area $^{12}$ and thus making contact with other-ethnics and immigrants more or less frequent. To more directly control for contact with immigrants rather than simply a diverse setting, we calculated the average distance between each township and Harare, Zimbabwe and Maputo, Mozambique and include that distance as a control. A township that is closer to these neighboring capitals is likely to have more immigrants, who are disproportionate targets of xenophobia (Hassim et al 2008). While immigrants disproportionately migrate to areas with the highest likelihood of employment, distance does influence settlement patterns, and we assume, all else equal, that immigrants will prefer a close area to a far area.

\footnotetext{
${ }^{12}$ We group Mdantsane and Umlazi together (Daveyton $=0$ for both locations) in this measure as they are both ethnically homogenous areas.
} 
To control for cultural threat, we measure the strength of ethnic identification using responses to the remaining MEIM questions to construct an ethnic strength score. We measure cultural threat in this way because the stronger one identifies with her ethnic group, the more likely she is to feel that her culture and way of life are under threat and thus more likely to hold prejudices against other groups. ${ }^{13}$ Responses to thirteen of the remaining MEIM questions were averaged to yield the ethnic strength score in the set [1,4]. This score is continuous and increasing in the degree to which the subject identifies with and values her ethnic group (a strong identity - an identity score closer to 4 - indicates that the individual positively identifies with her ethnic group and that her identity is important in her everyday life).

We also include controls for age, gender, ethnic group identity, and the year data was gathered. We include age because youth are more likely to hold prejudices against immigrants (i.e., Hassim et al 2008). There is also suggestive evidence that men and Zulus are more likely to be prejudiced toward immigrants (i.e. Crush 2000, Solomon and Schutte 2001); therefore, we add a dummy variable that indicates whether or not the subject is male and three dummy variables that indicate Zulu, Xhosa, and Other. ${ }^{14}$ We also include a control variable that indicates in which year the data was gathered (2009 or 2011) to control for differences in the datasets. Table A2 in Appendix A reports summary statistics for each variable.

\section{Analysis and Results}

\footnotetext{
${ }^{13}$ Further, we opted for this measure rather than asking people directly if they feel culturally threatened by immigrants (which suffers from response bias) or ask them to participate in yet another list experiment (cognitive burden).

${ }^{14}$ Ethnic identity was coded in this way because Zulus and Xhosas are the two largest and the most politically relevant black ethnic groups in South Africa.
} 
Using responses to the list experiments as the dependent variables, we run a series of difference of means tests on various demographically defined sub-samples to estimate the effect of economic threat on prejudice toward immigrants. Following the difference-in-means estimation, we estimate a more robust multivariate maximum likelihood regression model (Item Count Technique, ICT) on the data to address the loss of power that accompanies difference-inmeans tests. This multivariate regression approach to the analysis of list experiments allows us to analyze the full sample from our list experiment in a more robust and statistically efficient manner (Blair and Imai 2012).

\section{Comparing 2009 and 2011 Data}

Before presenting the analysis, we test for any systematic differences between the 2009 and 2011 data. We do this by conducting difference in means tests on observable characteristics between the two data sets and report the results in Table A4 in Appendix A, which shows that the two data sets are quite different.

While the two datasets are quite different on a number of observables, this is likely largely due to the differing recruitment procedures for the two samples. The 2009 sample was recruited to a central locale, and the 2011 survey was conducted at respondent's homes (and only in Daveyton). Respondents in both years were provided with payment for participation, but the payment was slightly higher in 2009 to incentivize respondents to come to the study lab. Thus, we should expect, as we see in Table A4, that the 2009 sample subjects would be younger, more likely to be unemployed, have lower incomes, and be less likely to have a private water source. Further, we expect that the 2011 sample is more representative of the Daveyton population given 
that respondents did not face as high a cost (transportation) to participate; therefore, it is unsurprising that there are other differences between the samples.

Appendix A presents a more detailed explanation of the differences in the datasets and presents tests regarding the appropriateness of pooling these two datasets. ${ }^{15}$ However, it is important to emphasize that assignment to treatment and control conditions was fully random in both study years, ${ }^{16}$ so in expectation treatment effects should reflect differences between conditions, which is the focus of the study. We include a dummy variable for study year to control for imbalances caused by the timing of treatment and the method of survey administration.

\section{Difference-in-Means Estimation for the List Experiments}

We first perform basic difference-in-means tests as is common with analysis of list experiment data (Kuklinski et al 1997). We begin our analysis with an investigation into the presence and pervasiveness of anti-immigrant sentiment among South Africans in our three sampled townships. In the top panel of Table 1, we clearly see that the average number of items that make people angry and influence individuals' vote choices are significantly higher for those in the treatment conditions regardless of how we partition the data. As discussed above, a

\footnotetext{
${ }^{15}$ While data was gathered in two different years and only in Daveyton in 2011, it is important to ensure that the main results hold for each year, for Daveyton, and for the locations for which we only have 2009 data to ensure that pooling the data is appropriate. We find that the main results hold in all of these individual datasets (see Appendix A, Section 6). Unfortunately, given power limitations, we are unable to estimate the full ICT analysis on each subsample. We also run Chow tests to detect any structural breaks between the 2009 and 2011 data, and we find no evidence of such breaks, which suggests that pooling the data is not likely to be problematic (see Appendix A, Section 6).

16 Table A6 and A7 in Appendix A present balance tests for each experiment.
} 
difference in the average number of items selected can be attributed to the sensitive item. If we use the full sample, only the 2009 data, only the 2011 data, or look at Daveyton or Mdantsane individually, we clearly see that people in the treatment conditions are angered by immigrants moving into their communities (Column 4). Only in Umlazi is there no significant difference. Across all data subsets in Panel A, we see that anti-immigrant politicians do influence individuals' vote choices. These data enable us to infer that 1) the residents of South Africa's townships are highly prejudiced toward immigrants and 2) that this prejudice influences their vote choices. This analysis is only suggestive because it overlooks important variation within the sample and does not control for confounders.

\section{[Table 1 Here]}

We now proceed to the difference-in-means tests probing the observable implications of economic threat theory. We estimate difference in means tests using the sub-samples of individuals based on water source, education, employment, income, and inter-group contact. For example, we took the individuals with a private water source in the control group and generated their average response to each list question and then compared that average to the average of those with a private water source in each of the treatment groups. The results of the tests are reported in Table 2.

\section{[Table 2 Here]}

First consider the significant results from within columns (5) and (6). Column (5) shows that immigrant prejudice is high regardless of water source, education level, income, and intergroup contact, suggesting that these variables are not key differentiators of prejudice in our sample. For example, if an individual who completed high school received the anger treatment, she is significantly more likely to choose the sensitive item, but this is also the case for those 
who did not complete high school and those who did at least some post-high school education. Stated differently: those with more education are not significantly more or less likely to hold prejudice toward immigrants than those with less education. However, the unemployed are more prejudiced against immigrants relative to the employed as measured by their mean increase in listing the sensitive item compared to the unemployed control group. More specifically, those unemployed respondents who receive the treatment condition are significantly likely (at the 0.01 level) to choose the sensitive item; however, when the employed respondents receive the sensitive item, they are not significantly more likely on average to choose the sensitive item.

Column (6) of Table 2 shows that immigrant prejudice does influence the vote choice of those who did not complete their high school education or completed more school than just high school, the unemployed, those with low incomes, and those with low inter-group contact. We come to these conclusions because those individuals with the previously mentioned attributes, when given the sensitive item, have significantly higher average responses to the list experiment question relative to those who received the treatment condition among the other sub-groups. Specifically, this is true for those who completed high school, the employed, those with high incomes, and those with high inter-group contact.

These results are tentative given the limitations of the difference in means tests: only evaluating covariates in isolation on relatively small sub-samples does not allow for a complete picture of the determinants of prejudice or its effects on vote choice and results in a loss of efficiency in estimation (Blaire and Imai 2012). Therefore, we now analyze the same data from the list experiment in a multivariate manner using ICT estimation.

\section{Item Count Technique (ICT) Estimation}


We employ Blaire's and Imai's (2012) maximum likelihood item count estimation technique (ICT) to further investigate the effect of economic threat on immigrant prejudice. ICT estimation also allows us to test the two main list experiment assumptions: the "no design effects" assumption and the "no liars" assumption. The assumption of "no design effects" assumes that that the addition of the sensitive item does not change a subject's response to the control items, and we find that this assumption holds for both treatment conditions in both experiments. The formal test for the "no design effects" assumption can be found in Appendix C. The "no liars" assumption states that people will honestly respond to the sensitive item. We address the "no liars" assumption by controlling for ceiling and floor effects in the ICT estimation (see a more detailed discussion of this control procedure in Appendix C).

The model we fit using the ICT method estimates coefficients for both the control and treatment items. The coefficients estimate the effect of the associated variable on the likelihood of answering affirmatively to either the control items or the sensitive item. The results of the maximum likelihood estimation are reported in Table 3.

First, consider Panel A of Table 3 to evaluate the determinants of prejudice toward immigrants moving into one's neighborhood. The results show support for economic threat theory: unemployment is a significant indicator of immigrant prejudice. The odds ratio of 3.89 provides a substantive interpretation of the effect of unemployment on immigrant prejudice: being unemployed makes an individual over 300 times more likely to be angered by immigrants moving into their community, all else equal. However, the other measures of economic threat are not significantly related to immigrant prejudice, which suggests that the competition over jobs and the insecurity brought on by unemployment are important factors in predicting antiimmigrant prejudice. In short, we find strong support for Hypothesis 1. 
In addition, the results reveal no statistically significant evidence that contact, culture threat, education, or the other variables explain immigrant prejudice in South Africa. It is also important to note that the results show that those who have more than primary education, are not Zulu or Xhosa, and participated in 2011 are significantly more likely to respond affirmatively to the control items (see the second column of Table 3). It seems that these individuals are significantly more angered by at least one of the control items than the more educated, the Zulu and Xhosa, and those sampled in 2009. The finding concerning participation in 2011 shows that the control issues had possibly become more relevant to people in the prior two years, possibly due to more pressure on individuals as a result of the global recession (Mail and Gaurdian 2011).

[Table 3 Here]

While the results offer some evidence that economic threat is correlated with immigrant prejudice, the question remains: does immigrant prejudice influence vote choice? In other words, given the high degree of prejudice toward immigrants that the study has uncovered thus far, do these feelings influence the prospective political choices of voters and more so for the unemployed? The first model in Table 3, Panel B clearly shows that only being a member of one of South Africa's smaller ethnic groups ("Other Ethnic", meaning not Zulu or Xhosa) makes an individual significantly more likely to respond that anti-immigrant stances influenced their vote choice in the recent national elections. However, none of the variables, except being part of a smaller ethnic group, predict choosing the sensitive item in our list experiment. We interpret these results as evidence that prejudice that results from a lack of contact, culture threat, economic threat, and so forth does not influence individuals' vote choices. Therefore, although the unemployed clearly feel greater prejudice toward immigrants likely due to the economic threat that they pose in the form of greater competition for jobs, this feeling of economic threat 
among the unemployed does not seem to translate into greater prospective support for antiimmigrant politicians from the unemployed.

To summarize, we find support for two propositions. First, one's economic condition (specifically unemployment) is the most robust predictor of anti-immigrant prejudice among our sample. Second, while anti-immigrant sentiment is quite high in our sample, these sentiments do not significantly influence one's prospective political preferences even for those who have stronger anti-immigrant sentiments. This is most clearly illustrated by the fact that the unemployed are significantly more likely to express anger over immigrants moving into their community and yet not more likely to vote for a party/candidate that seeks to stop immigration.

\section{Conclusion}

This study sought to uncover the effect of economic threat on immigrant prejudice. Through various estimation techniques, the current study finds that unemployment is associated with an increase in anti-immigrant sentiments, which provides support for much of the qualitative literature on immigrant prejudice in South Africa: competition over jobs among the

unemployed appears to correlate with prejudice toward immigrants. Importantly, this study provides evidence that is more generalizable and less fraught with response bias than past studies. As such, policy-makers can now have a clearer goal in addressing anti-immigrant sentiment in South Africa: public opinion and African unity campaigns (both approaches that have been tried) are likely to have little effect. The most promising way to combat xenophobia is to bring about economic growth and jobs.

Importantly, this study has found that while anti-immigrant sentiments are quite widespread among those living in South Africa's townships, this issue is not important when 
determining how people report they will vote. It is puzzling that South African politicians have not taken advantage of anti-immigrant sentiments to increase their voter base. This could likely be the case for a number of reasons.

First, since 1994, South Africa has established a norm of non-discrimination. Since the end of apartheid, it is no longer acceptable for politicians to discriminate in their speech. This then limits politician's ability to strategically exploit these sentiments for political gain. Second, given that South Africans face many more imminent challenges such as unemployment, security, reliable public services that are not such pressing concerns in many European countries, it makes sense that anti-immigrant sentiments are not an important determinant of vote choice. More immediate concerns may be displacing immigration as a key political issue even though immigration does come with a basket of economic concerns. Third, these results could be due to the electoral dominance of the African National Congress (ANC): because many are set on voting for the ANC, the marginal impact of immigration may not be enough to sway voters and therefore not an attractive strategy for an electorally dominant party like the ANC. However, a small party has recently formed, the South Africa First party, whose platform is anti-immigrant, which could potentially change the electoral relevance of anti-immigrant appeals and incentivize the ANC to adopt such stances (see Meguid (2005)). Whatever the explanation, it is clear from this study that the role of anti-immigrant prejudice in politics is different in a developing world context compared to Europe.

While the sources of prejudice in South Africa clearly differ from those found in Europe, can we generalize these findings to other developing countries? We speculate that we can, but do so with appropriate caveats that a careful examination of context is warranted. India is quite similar to South Africa in key ways. Both have high economic inequality, high levels of 
xenophobia seemingly driven by employment competition, and a ruling party that does not effectively combat xenophobia (Crush and Ramachandran 2010). However, major parties in India have campaigned with promises to deport Bangladeshis and seal the boarders. Therefore, we are likely to see similar economic roots of xenophobia in India, but we are also likely to see a correlation between xenophobia and vote choice in India that we do not see in South Africa.

These results may readily apply to Libya in the 1990s and early 2000s. Major violence against immigrants erupted in late 2000 (the initial impetus is unknown), which continued for about three months and led to the Nigerian and Ghanaian governments' evacuating hundreds of their nationals from Libya (Crush and Ramachandran 2009). These attacks followed a steady increase in unemployment since 1995, which peaked in 2000/2001 at 20\%. While a direct link between unemployment and these attacks has not been established, given the analysis presented here, unemployment likely played a role. Further, Gaddafi's regime at the time was actively promoting African unity as Gaddafi presented himself as the leader of the trans-African movement. There was no active political support or encouragement of anti-immigrant sentiments from the ruling party (or other parties) and therefore it is not likely that anti-immigrant appeals were politically important.

Given Adida's (2014) work, the results here may apply in Benin, Ghana, and Niger where locals tend to shun/discriminate against immigrants (even those who are co-ethnics) because, among other considerations, they threaten the current balance of economic power. However, the current study's results are not likely to apply to contexts like the Ivory Coast in which the ruling party has in the past activity encouraged violence against foreigners driven by a notion of national identity and the right to Ivorian citizenship. Not only is immigration more politicized but culture threat is likely more important in such contexts. 
It is worth noting a key limitation of the study as we conclude and anticipate future studies. While we took pains in our research to select a diverse sample at random in three locales, we returned two years later to the most diverse research site and increased the size of the subject pool through a different technique of administering the survey: door to door vs. recruitment to a central location. This produced systematic differences in the composition of the subject pool and also in the average values of the dependent variables. While this might be a significant problem in a survey seeking a representative national sample to estimate general national attitudes, we are less concerned here because the key quantity of interest was the treatment effects of the list experiment and because empirical tests suggest that pooling that data is appropriate. In controlling for the fixed effects of the two study years, we still find significant treatment effects that appear to be meaningfully associated with unemployment but not to other covariates.

This study produces more systematic evidence on the underlying sources of xenophobia in the Global South. The present design offers a superior measurement strategy for identifying xenophobia in South Africa than has previously been employed. The finding that unemployment drives anti-immigrant sentiment is a potentially important conclusion that suggests that the sources of xenophobia in at least one developing country, South Africa, may be quite different than in developed nations, given past research that finds unemployment specifically does not predict anti-immigrant sentiments in Europe (Schneider 2008). These findings suggest caution in generalizing conclusions about the sources of political attitudes from the research in wealthy, industrialized countries to poorer, developing nations.

\section{References}


Adida, Claire L, Immigrant Exclusion and Insecurity in Africa: Co-Ethnic Strangers (Cambridge: Cambridge University Press, 2014).

Afrobarometer Data, South Africa, Round 6, 2016, available at http://www.afrobarometer.org.

Al Jazeera, "Anti-Immigrant Violence Spreads in South Africa," April 18, 2015a, accessed March 30, 2017, http://www.aljazeera.com/news/2015/04/fear-grips-foreignersjohannesburg-150417081633360.html.

Al Jazeera, "South Africa Deploys Army to Quell Xenophobic Violence," April 21, 2015b, accessed March 30, 2017. <http://www.aljazeera.com/news/2015/04/south-africadeploys-army-quell-violence-150421115836190.html>

Allport, Gordon W, The Nature of Prejudice (Reading, MA: Addison-Wesley, 1954).

Bekker, Simon, Ilse Eigelaar-Meets, Gary Eva, and Caroline Poole. 2008. "Xenophobia and Violence in South Africa: A Desktop Study of the Trends and a Scan of Explanations Offered." Working paper University of Stellenbosch (2008).

Blair, Graeme and Kosuke Imai, "Statistical analysis of List Experiments," Political Analysis 20 (2012): 47-77.

Blinder, Scott, Robert Ford, and Elisabeth Ivarsflaten, "The Better Angels of Our Nature: How the Anti-prejudice Norm Affects Policy and Party Preferences in Great Britain and Germany," American Journal of Political Science. 57(2013): 841-857.

Bobo, Lawrence and Fredrick Licari, "Education and Political Tolerance: Testing the Effects of Cognitive Sophistication and Target Group Affect," Public Opinion Quarterly 53 (1989): 285-308.

Brown, Rupert, Prejudice: Its Social Psychology Second Edition (Wiley-Blackwell, 2010).

Capozza, Dora, and Rupert Brown, Social Identity Processes: Trends in Theory and Research (London: Sage, 2000).

Chandler, Charles R. and Yung-mei Tsai, "Social factors influencing immigration attitudes: an analysis of data from the General Social Survey," The Social Science Journal 38 (2001): 177-188.

Citrin, Jack, Donald Green, Christopher Muste, and Cara Wong, "Public Oppinion Toward Immigration Reform: The Role of Economic Motivations" Journal of Politics 59(1997): 858-881.

Croucher, Sheila, "South Africa's Illegal Aliens: Constructing National Boundaries in a PostApartheid State." Ethnic and Racial Studies 21 (1998): 639-660. 
Crush, Jonathan and Sujata Ramachandran, "Xenophobia, International Migration and Development." Human Development Research Paper No. 2009/49, UNDP, New York (2009).

Crush, Jonathan and Sujata Ramachandran, "Xenophobia, International Migration and Development.” Journal of Human Development and Capabilities 11 (2010): 209-228.

Crush, Jonathan, “The Dark Side of Democracy: Migration, Xenophobia and Human Rights in South Africa." International Migration 38 (2000): 103-133.

Esses, Victoria M., John F. Dovidio, Lynne, M. Jackson, and Tamara L. Armstrong, "The Immigration Dilemma: The Role of Perceived Group Competition, Ethnic Prejudice, and National Identity" Journal of Social Issues 57 (2001): 389-412.

Fearon, James, "Ethnic and Cultural Diversity by Country" Journal of Economic Growth. 8 (2003): 195-222.

Fetzer, Joel S, Public Attitudes toward Immigration in the United States, France, and Germany (Cambridge: Cambridge University Press, 2000).

Ford, R, "Acceptable and Unacceptable Immigrants: How Opposition to Immigration in Britain is Affets by Migrants' Region of Origin" Journal of Ethnic and Migration Studies 37 (2011): 1017-1037.

Glynn, Adam N. 2013. "What can we learn with Statistical Truth Serum?: Design and Analysis of the List Experiment," Public Opinion Quarterly 77 (2013): 159-172.

Green, Donald P. and Rachel L. Seher, "What Role Does Prejudice Play in Ethnic Politics," American Review of Political Science 6 (2003): 509-531.

Hainmueller, Jens and Dominik Hangartner, "Who Gets a Swiss Passport? A Natural Experiment in Immigrant Discrimination,” American Political Science Review. 107(2013): 159-187.

Hainmueller, Jens and Michael J. Hiscox, "Education Preferences: Explaining Attitudes Toward Immigration in Europe," International Organization 61 (2007): 399-442.

Hainmueller, Jens and Daniel J. Hopkins, "Political Attitudes Toward Immigrants" Annual Review of Political Science. 17 (2014).

Hanson, Gordon H., Kenneth Sheve, and Matthew J. Slaughter, "Public Finance and Individual Preferences over globalization Strategies," Economics and Politics 19 (2007): 1-33.

Hassim, Shireen, TawanaKupe, Eric Worby (eds), Go Home or Die Here: Violence, Xenophobia, and the Reinvention of Difference in South Africa(Johannesburg: Wits University Press, 2008). 
Hello, Evelyn, Peer Scheepers, and Merove Gijsberts, "Education and Ethnic Prejudice in Europe: Explanations for Cross-National Variances in the Educational Effect on Ethnic Prejudice" Scandinavian Journal of Educational Research 46 (2002): 5-24.

Hello, Evelyn, Peer Scheepers, and Peter Sleegers, "Why the More Educated are Less Inclined to Keep Ethnic Distance: An Empirical Test of Four Explanations," Ethnic and Racial Studies 29 (2006): 959-985.

Hopkins, Daniel J., "Politicized Places: Explaining Where and When Immigrants Provoke Local Opposition," American Political Sciecne Review 104 (2010): 40-60.

Huddy, Leonie, "From Social to Political Identity: Implications for Political Psychology," Political Psychology 22 (2001): 127- 56.

Koopmans, Ruud, "Explaining the Rise of Racist and Extreme right Violence in Western Europe: Grievance of Opportunity?" European Journal of Political Research 30 (1996): 185-216.

Kopstein, Jeffery S. and Jason Wittenberg, "Does Familiarity Breed Contempt? Inter-Ethnic Contact and Support for Illiberal Parties." Journal of Politics 71(2009): 414-428.

Kramon, Eric and Keith Weghorst, "Measuring Sensitive Attitudes in Developing Countries: Lessons from Implementing the List Experiment," Experimental Political Scientist 3 (2012): 14-26.

Kuklinski, James H., Michael D. Cobb, and Martin Gilens. "Racial Attitudes and the "New South'," Journal of Politics 59 (1997): 323-349.

Landau, Loren B, "Loving the Alien? Citizenship, Law, and the Future in South Africa's Demonic Society" African Affairs (2010): 1-18.

Luttmer, Erzo F. P, "Group Loyalty and the Taste of Redistribution," Journal of Political Economy 109 (2001): 500-528.

Mayda, Anna Maria, "Who is Against Immiration? A Cross-Country Investigation of Individual Attitudes Toward Immigrants," The Review of Economics and Statitistics 88 (2006): 510530.

Meguid, Bonnie, "Competition Between Unequals: The Role of Mainstream Party Strategy in Niche Party Success," American Political Science Review 99 (2005): 347-359

McLaren, Lauren, and Mark Johnson, "Resources, Group Conflict, and Symbols: Explaining Anti-Immigration Hostility in Britain," Political Studies 55 (2007):709-732.

Misago, Jean Pierre, Lauren B. Landau, and Tamlyn Monson Toward Tolerance, Law, and Dignity: Addressing Violence against Foreign Nationals in South Africa. International 
Organization for Migration (IOM) Report (Johannesburg: University of Witwatersrand, 2009).

Mudde, Cas, "Radical Right Parties in Europe: What, Who, Why?" Participation 35 (2011):1215

Nicolson, Greg, "SAHRC: Let's Talk About Xenophobia," Daily Maverick, April 9, 2015, accessed October 10, 2016, http://www.dailymaverick.co.za/article/2015-04-09-sahrclets-talk-about-xenophobia/\#.VqY4K3i9w0t.

Oliver, J. Eric and Tali Mendelberg, "Reconsidering the environmental Determinants of White Racial Attitudes.” American Journal of Political Science 44 (2000): 574-589.

Phinney, Jean S, “The Multigroup Ethnic Identity Measure: A New Scale for use with Diverse Groups,” Journal of Adolescent Research 7 (1992): 156-176.

Rocha, Rene R. and Rodolfo Espino, "Racial Threat, Residential Segregation, and the Policy Attitudes of Anglos.” Political Research Quarterly 62 (2009): 415-426.

Scheve, Kenneth F. and Matthew J. Slaughter, "Labor Market Competition and Individual Preferences over Immigration Policy," The Review of Economics and Statistics 83 (2001): 133-145.

Schmid, Katharina, Nicole Tausch, Miles Hewstone, Joanne Hughes, and Ed Cairns, "The Effects of Living in Segregated vs. Mixed Areas in Northern Ireland: A Simultaneous Analysis of Contact and Threat Effects in the Context of Micro-Level Neighbourhoods," International Journal of Conflict and Violence 2 (2008): 56-71.

Schneider, Silke, "Anti-Immigrant Attitudes in Europe: Out-group Size and Perceived Ethnic Threat," European Sociological Review 24 (2008): 53-67.

Sides, John and Jack Citrin, "European Opinion About Immigration: The Role of IdentFities, Interests and Information," British Journal of Political Science 37 (2007): 477-504.

Sniderman, Paul M., LoukHagendoorn, and Markus Prior, "Predisposition Factors and Situational Triggers: Exclusionary Reactions to Immigrant Minorities." American Political Science Review 98 (2004): 35-49.

Sniderman, Paul M., Richard A. Brody, and James H. Kuklinski, "Policy Reasoning and Political Values: The Problem of Racial Equality." American Journal of Political Science 28 (1984): 75-94.

Solomon, Hussein, and Charles Schutte, "Of Myths and Migration," In The Long Roads to Peace, Joseph Rotblat (ed) (London: World Scientific Publishing Co. Pty. Ltd, 2001). 
Statistics South Africa.

Census 2001. Available at: <http://www.statssa.gov.za/census01/html/RSA Primary.pdf>. 23 April 2008.

Taijfel, Henri, Human Groups and Social Categories: Studies in Social Psychology (New York: Cambridge University Press, 1981).

United Nations, World Migration Report, 2013, accessed May 5, 2014, http://www.un.org/en/development/desa/population/publications/pdf/migration/migration report2013/Full_Document final.pdf.

Van der Brug, Wouter, Meindert Fennema, and Jean Tilly, "Anti-immigrant Parties in Europe: Ideological of Protest Vote?” European Journal of Political Research. 37 (2000): 77-102.

Van der Brug, Wouter, Meindert Fennema, and Jean Tillie, "Why Some Anti-Immigrant Parties Fail and Others Succeed. A Two-Step Model of Aggregate Electoral Support." Comparative Political Studies. 38 (2005): 537-573.

Wagner, Markus and Thomas Meyer, "The Radical Right as Niche Parties? The Ideological Landscape of Party Systems in Western Europe, 1980-2014," Political Studies 65 (2017): 84-107.

Werts, Han, Peer Scheepers, and Marcel Lubbers, "Euro-Scepticism and Radical Right-Wing Voting in Europe 2002-2008," European Union Politics (2012).

Whitaker, Beth, "Playing the Immigrant Card: The Politics of Exclusion in Cote d'Ivoire and Ghana." Commonwealth and Comparative Politics 53 (2015): 274-293.

Whitaker, Beth and Jason Giersch "The Politics of Exclusion: Explaining Anti-Immigrant Attitudes in Africa" Working paper University of North Carolina at Charlotte (2015).

Wilkinson, Kate, "Do Five Million Immigrants Live in South Africa?" Mail and Guardian, May 6, 2015, accessed May 7 2015, http://mg.co.za/article/2015-05-06-do-5-millionimmigrants-live-in-sa 
Figure 1:

Question Wording for List Experiment 1 (Anger Experiment)

Question: How many of the following make you angry?

A. Politicians who do not keep their promises

B. The unemployment rate

C. High prices (for example: food and gas prices)

D. High crime rates

Treatment Item:

E. Immigrants moving into your community

Question Wording for List Experiment 2 (Voting Experiment)

Question: How many of the following influenced your vote in the recent national elections?

A. Crime reduction issues

B. Your party affiliation

C. Poverty reduction promises

D. Housing issues

Treatment Item:

E. Candidate or party promises to stop immigration 
Table 1: Does prejudice against immigrants exist?

\begin{tabular}{|c|c|c|c|c|c|c|}
\hline & \multicolumn{2}{|c|}{ Anger Experiment } & \multicolumn{2}{|c|}{ Vote Experiment } & \multicolumn{2}{|c|}{ Difference: } \\
\hline & & & & & Anger & \\
\hline & Control & Treatment & Control & Treatment & $\begin{array}{c}\text { Toward } \\
\text { Immigrants }\end{array}$ & $\begin{array}{c}\text { Voting Against } \\
\text { Immigrants }\end{array}$ \\
\hline & $(1)$ & $(2)$ & $(3)$ & $(4)$ & $(5: 1-2)$ & $(6: 3-4)$ \\
\hline \multirow[t]{3}{*}{ Full Sample } & 2.93 & 3.56 & 2.81 & 3.08 & $-0.63 * * *$ & $-0.28 * *$ \\
\hline & $(0.06)$ & $(0.07)$ & $(0.07)$ & $(0.08)$ & & \\
\hline & 356 & 369 & 358 & 367 & & \\
\hline \multirow[t]{3}{*}{2009} & 2.52 & 3.19 & 2.94 & 3.20 & $-0.67 * * *$ & $-0.25^{*}$ \\
\hline & $(0.09)$ & $(0.10)$ & $(0.09)$ & $(0.11)$ & & \\
\hline & 191 & 208 & 199 & 210 & & \\
\hline \multirow[t]{3}{*}{2011} & 3.4 & 4.03 & 2.64 & 2.94 & $-0.63 * * *$ & $-0.30 *$ \\
\hline & $(0.07)$ & $(0.10)$ & $(0.11)$ & $(0.12)$ & & \\
\hline & 165 & 161 & 159 & 157 & & \\
\hline \multirow[t]{3}{*}{ Daveyton } & 3.15 & 3.77 & 2.80 & 3.06 & $-0.62 * * *$ & $-0.26 * *$ \\
\hline & $(0.07)$ & $(0.09)$ & $(0.09)$ & $(0.09)$ & & \\
\hline & 253 & 245 & 243 & 249 & & \\
\hline \multirow[t]{3}{*}{ Mdantsane } & 2.44 & 3.25 & 2.59 & 3.43 & $-0.81 * * *$ & $-0.84 * * *$ \\
\hline & $(0.16)$ & $(0.19)$ & $(0.19)$ & $(0.21)$ & & \\
\hline & 54 & 55 & 54 & 49 & & \\
\hline \multirow[t]{3}{*}{ Umlazi } & 3.03 & 2.94 & 2.33 & 3.06 & 0.09 & $-0.73 * * *$ \\
\hline & $(0.16)$ & $(0.21)$ & $(0.18)$ & $(0.18)$ & & \\
\hline & 61 & 69 & 49 & 69 & & \\
\hline
\end{tabular}


Table 2: Difference of Means Tests between the following Groups:

Control and Treatment group responses to Anger and Voting List Experiments

\begin{tabular}{|c|c|c|c|c|c|c|}
\hline & \multicolumn{2}{|c|}{ Anger Experiment } & \multirow{2}{*}{\multicolumn{2}{|c|}{ Vote Experiment }} & \multicolumn{2}{|c|}{ Difference: } \\
\hline & & & & & Anger & \\
\hline & Control & Treatment & Control & Treatment & $\begin{array}{c}\text { Toward } \\
\text { Immigrants }\end{array}$ & $\begin{array}{l}\text { Voting Against } \\
\text { Immigrants }\end{array}$ \\
\hline & $(1)$ & $(2)$ & (3) & (4) & $(5: 1-2)$ & $(6: 3-4)$ \\
\hline \multicolumn{7}{|l|}{ Water Source } \\
\hline \multicolumn{7}{|l|}{ Public Water } \\
\hline \multirow[t]{2}{*}{ Source } & 2.86 & 3.45 & 2.96 & 3.03 & $-0.59 * * *$ & $-0.34 *$ \\
\hline & $\begin{array}{c}(0.11) \\
118\end{array}$ & $\begin{array}{c}(0.14) \\
121\end{array}$ & $\begin{array}{c}(0.11) \\
113\end{array}$ & $\begin{array}{c}(0.13) \\
131\end{array}$ & & \\
\hline \multicolumn{7}{|l|}{ Private Water } \\
\hline \multirow[t]{3}{*}{ Source } & 2.97 & 3.61 & 2.86 & 3.12 & $-0.64 * * *$ & $-0.26^{*}$ \\
\hline & $(0.07)$ & $(0.09)$ & $(0.09)$ & $(0.10)$ & & \\
\hline & 238 & 247 & 245 & 235 & & \\
\hline \multicolumn{7}{|l|}{ Employment } \\
\hline \multirow[t]{3}{*}{ Unemployed } & 2.82 & 3.58 & 2.83 & 3.10 & $-0.77 * * *$ & $-0.26^{* *}$ \\
\hline & $(0.07)$ & $(0.08)$ & $(0.08)$ & $(0.09)$ & & \\
\hline & 271 & 286 & 286 & 285 & & \\
\hline \multirow[t]{3}{*}{ Employed } & 3.28 & 3.45 & 2.69 & 3.04 & -0.18 & -0.34 \\
\hline & $(0.11)$ & $(0.16)$ & $(0.15)$ & $(0.17)$ & & \\
\hline & 85 & 83 & 72 & 82 & & \\
\hline \multicolumn{7}{|l|}{ Income } \\
\hline \multirow[t]{3}{*}{ Low Income } & 2.53 & 3.17 & 2.81 & 3.20 & $-0.64 * * *$ & $-0.39^{* *}$ \\
\hline & $(0.10)$ & $(0.12)$ & $(0.10)$ & $(0.12)$ & & \\
\hline & 151 & 158 & 146 & 164 & & \\
\hline \multirow[t]{3}{*}{ High Income } & 3.22 & 3.85 & 2.81 & 3.00 & $-0.62 * * *$ & -0.19 \\
\hline & $(0.07)$ & $(0.09)$ & $(0.10)$ & $(0.11)$ & & \\
\hline & 205 & 211 & 212 & 203 & & \\
\hline \multicolumn{7}{|l|}{ Education } \\
\hline Did not Complete & 2.82 & 3.57 & 2.66 & 3.05 & $-0.75 * * *$ & $-0.39 * *$ \\
\hline \multirow[t]{2}{*}{ High School } & $(0.10)$ & $(0.12)$ & $(0.11)$ & $(0.12)$ & & \\
\hline & 140 & 160 & 146 & 148 & & \\
\hline Completed High & 3.03 & 3.55 & 2.82 & 2.91 & $-0.52 * * *$ & -0.09 \\
\hline \multirow{2}{*}{ School } & $(0.09)$ & $(0.12)$ & (013) & $(0.13)$ & & \\
\hline & 148 & 138 & 140 & 149 & & \\
\hline \multirow[t]{3}{*}{ Tertiary Education } & 2.93 & 3.54 & 3.06 & 3.51 & $-0.62 * * *$ & $-0.45^{* *}$ \\
\hline & $(0.14)$ & $(0.17)$ & $(0.14)$ & $(0.18)$ & & \\
\hline & 67 & 70 & 71 & 70 & & \\
\hline \multicolumn{7}{|l|}{ Inter-Group Contact } \\
\hline \multirow[t]{3}{*}{ Low Contact } & 2.61 & 3.29 & 2.63 & 3.33 & $-0.68 * * *$ & $-0.70 * * *$ \\
\hline & $(0.14)$ & $(0.18)$ & $(0.16)$ & (0.19) & & \\
\hline & 80 & 73 & 70 & 70 & & \\
\hline \multirow[t]{3}{*}{ High Contact } & 3.04 & 3.56 & 3.02 & 3.37 & $-0.52 * *$ & -0.35 \\
\hline & $(0.14)$ & $(0.19)$ & $(0.17)$ & $(0.20)$ & & \\
\hline & 54 & 54 & 59 & 47 & & \\
\hline
\end{tabular}

Table 2 reports difference of means tests of the average response rates of treatment and control groups to the Anger List Experiment question (see Figure 1).

$* * * \mathrm{p}<.01, * * \mathrm{p}<.05, * \mathrm{p}<.1$. 
Table 3: ICT Estimation Results

Dependent Variable: Affirmative Response to Sensitive/Control Items

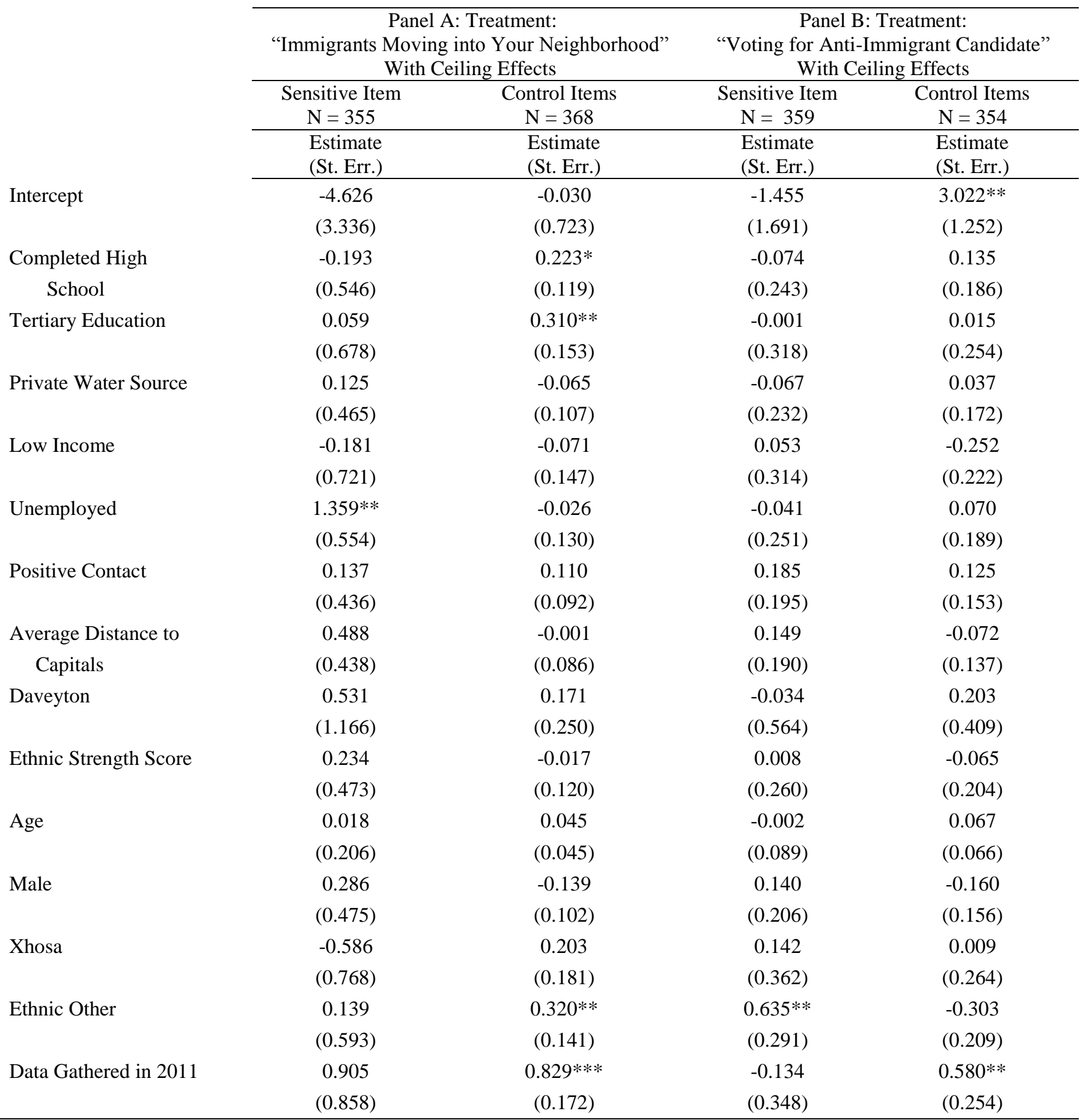

Table 3 reports the results of ICT estimation for the determinants of affirmative responses to control and immigrant treatment groups and to control and ethnic president treatment groups, respectively.

$* * * \mathrm{p}<.01, * * \mathrm{p}<.05, * \mathrm{p}<.1$. 